\title{
Targeting ADAM-17 with an inhibitory monoclonal antibody has antitumour effects in triple-negative breast cancer cells
}

F Caiazza ${ }^{*}{ }^{1}$, P M McGowan ${ }^{1}$, M Mullooly ${ }^{1}$, A Murray ${ }^{1}$, N Synnott ${ }^{1}$, N O'Donovan ${ }^{2}$, L Flanagan ${ }^{1}$, C J Tape ${ }^{3,4}$, G Murphy ${ }^{3}$, J Crown ${ }^{5}$ and M J Duffy ${ }^{1,6}$

${ }^{1}$ UCD School of Medicine and Medical Science, Conway Institute of Biomolecular and Biomedical Research, University College Dublin, Dublin, Ireland; ${ }^{2}$ National Institute for Cellular Biotechnology (NICB), Dublin City University, Dublin, Ireland; ${ }^{3}$ Department of Oncology, Cancer Research UK Cambridge Institute, University of Cambridge, Li Ka Shing Centre, Cambridge, UK; ${ }^{4}$ Cell Communication Team, Division of Cancer Biology, The Institute of Cancer Research, London, UK; ${ }^{5}$ Department of Medical Oncology, St Vincent's University Hospital, Dublin, Ireland and ${ }^{6}$ UCD Clinical Research Centre, St Vincent's University Hospital, Dublin, Ireland

Background: Identification and validation of a targeted therapy for triple-negative breast cancer (TNBC), that is, breast cancers negative for oestrogen receptors, progesterone receptors and HER2 amplification, is currently one of the most urgent problems in breast cancer treatment. EGFR is one of the best-validated driver genes for TNBC. EGFR is normally activated following the release of ligands such as TGF $\alpha$, mediated by the two MMP-like proteases ADAM (a disintegrin and metalloproteinase)-10 and ADAM-17. The aim of this study was to investigate the antitumour effects of a monoclonal antibody against ADAM-17 on an in vitro model of TNBC.

Methods: We investigated an inhibitory cross-domain humanised monoclonal antibody targeting both the catalytic domain and the cysteine-rich domain of ADAM17-D1(A12) in the HCC1937 and HCC1143 cell lines.

Results: D1(A12) was found to significantly inhibit the release of TGF $\alpha$, and to decrease downstream EGFR-dependent cell signalling. D1(A12) treatment reduced proliferation in two-dimensional clonogenic assays, as well as growth in three-dimensional culture. Furthermore, D1(A12) reduced invasion of HCC1937 cells and decreased migration of HCC1143 cells. Finally, D1(A12) enhanced cell death in HCC1143 cells.

Conclusion: Our in vitro findings suggest that targeting ADAM-17 with D1(A12) may have anticancer activity in TNBC cells.

In recent years, research on new cancer treatments has shifted from the use of cytotoxic agents to targeted therapies, that is, targeting specific genes that are causally involved in driving cancer growth and progression. Among the most successfully targeted genes are two members of the HER family, EGFR and HER2. Thus, at present, there are four approved anti-HER2 treatments for breast cancer. These include the monoclonal antibodies, trastuzumab and pertuzumab, the monoclonal antibody conjugate, trastuzumab-emtansine (T-DM1) and the tyrosine kinase inhibitor, lapatinib (Jelovac and Emens, 2013). Similarly, multiple anti-EGFR therapies are available for advanced colorectal (Caiazza et al, 2015) and non-small cell lung cancer (Heuckmann et al, 2012). In addition to the currently approved anti-HER therapies, several ongoing clinical trials are investigating diverse proteins downstream of the HER receptors as potential targets for the treatment of different cancers. These targets/putative targets include PI3K, AKT, BRAF and mTOR ( $\mathrm{Ma}$ and $\mathrm{Hu}$, 2013; Ocaña et al, 2013). 
Compared with the extensive investigations focusing on proteins downstream of EGFR-HER2, relatively little work has been carried out on targeting upstream genes/proteins. With the exception of HER2, HER family members are normally activated following the release of ligands such as TGF $\alpha$, amphiregulin, HB-EGF, epiregulin, epigen, EGF and betacellulin. The release and activation of these ligands is catalysed by two matrix metalloproteinases of the ADAMs (a disintegrin and metalloproteinase) family, ADAM-10 and ADAM-17 (Sahin et al, 2004; Sahin and Blobel, 2007; Murphy, 2008). Of these two ADAMs, ADAM-17 appears to be the more important, as this protease is responsible for the release of TGF $\alpha$, amphiregulin, HB-EGF, epiregulin, epigen, while ADAM-10 activates both EGF and betacellulin (Sahin et al, 2004; Sahin and Blobel, 2007; Gooz, 2010).

Both we (McGowan et al, 2007) as well as others (Borrell-Pagès et al, 2003; Kenny and Bissell, 2007; Duffy et al, 2009a, b) have previously shown that ADAM-17 is involved in the formation and/or progression of breast cancer. Indeed, ADAM-17 has been found to be a potent and independent predictor of disease outcome in patients with breast cancer (McGowan et al, 2008). Consistent with these findings, targeting ADAM-17 or both ADAM-10 and ADAM-17 with selective low-molecular-weight inhibitors was found to block the growth of breast cancer cells both in vitro and in vivo (Fridman et al, 2007b; Giricz et al, 2013; McGowan et al, 2013). In contrast to low-molecular-weight inhibitors, the use of monoclonal antibodies against ADAM-17 might be expected to result in more specific targeting.

Recently, an inhibitory humanised monoclonal antibody against ADAM-17 was described (Tape et al, 2011). The antibody, which was named D1(A12), was found to bind to both the catalytic domain and the disintegrin/cysteine-rich domain of ADAM-17 and to inhibit the proteolysis of several ADAM-17 substrates (Tape et al, 2011; Richards et al, 2012). Furthermore, D1(A12) blocked tumour growth in an animal model of ovarian cancer (Richards et al, 2012).

The aim of this study was therefore to investigate D1(A12) as a potential therapeutic strategy for breast cancer. As targeted therapy is currently available for the majority of patients with breast cancer, that is, hormonal therapy for oestrogen receptor (ER)-positive patients and anti-HER2 therapy for HER2-positive patients, we focused on the molecular subform of breast cancer for which targeted therapy is currently unavailable, that is, the subgroup negative for ER, progesterone receptors (PRs) and HER2 amplification. As this subgroup of breast cancer patients is negative for ER, PR and HER2, it is referred to as triple-negative breast cancer (TNBC).

\section{MATERIALS AND METHODS}

Cell lines and reagents. The TNBC cell lines, HCC1143, BT20, Hs578t, MDA-MB-231, MDA-MB-468 and HCC1937 were obtained from the American Tissue Culture Collection. Hs578i8 cells were supplied by Dr Susan McDonnell, University College Dublin (Hughes et al, 2008). All cell lines were grown in RPMI1640, supplemented with $10 \%$ fetal bovine serum, $1 \%$ penicillin/streptomycin and $1 \%$ fungizone (all obtained from Invitrogen Life Technologies, Carlsbad, CA, USA) and maintained in a $37^{\circ} \mathrm{C} \mathrm{CO} \mathrm{CO}_{2}$ humidified incubator. Cell line identity was confirmed by analysis of Short Term Repeat loci, and cells were routinely tested for mycoplasma infection. The selective ADAM-17 inhibitor, PF-5480090 (PF-548), was provided by Pfizer (Cork, Ireland) (Zhang et al, 2004). The rabbit polyclonal ADAM-17 antibody was obtained from Abcam (Cambridge, UK), and the human IgG control from R\&D Systems (Abingdon, UK). Phorbol12-myristate-13-acetate (PMA) was obtained from Sigma-Aldrich
(Arklow, Ireland), while cetuximab (Erbitux, Merck KGaA, Darmstadt, Germany) and trastuzumab (Herceptin, Roche, Clairecastle, Ireland) were supplied by the Pharmacy Department at St Vincent's University Hospital, Dublin, Ireland. The antiADAM-17 monoclonal antibody, D1(A12) was developed and prepared by Christopher Tape (Cambridge, UK). Isolation and purification of this antibody has been previously described (Tape et al, 2011).

TGF $\alpha$-shedding assay. Cells were grown in 24-well plates until subconfluent, pre-incubated with antibodies/inhibitor for $1 \mathrm{~h}$ and treated with $1 \mu \mathrm{M}$ PMA for $1 \mathrm{~h}$. Levels of TGF $\alpha$ were determined in conditioned media by ELISA (R\&D Systems). Concentrations were interpolated from a standard curve using the five-parameter logistic model with Readerfit (http://readerfit.com).

Protein isolation and immunoblotting. Cells were lysed in RIPA buffer $(150 \mathrm{~mm} \mathrm{NaCl}, 50 \mathrm{~mm}$ Tris- $\mathrm{HCl}, 1 \%$ Triton, $0.5 \%$ sodium deoxycholate and $0.1 \%$ SDS) supplemented with a protease and phosphatase inhibitor cocktail (Roche Applied Science, Burgess Hill, UK) and $1 \mathrm{~mm}$ PMSF (Sigma-Aldrich). Total proteins were separated on $10 \%$ SDS-PAGE gels and transferred to PVDF using a semi-dry system (Invitrogen, Paisley, UK). Membranes were preblocked with $5 \%$ low-fat dry milk in TBS-T and incubated with the indicated primary antibodies (Cell Signaling, Danvers, MA, USA) and either rabbit (Sigma-Aldrich) or mouse (Cell Signaling) horseradish peroxidase-conjugated secondary antibodies. Proteins were visualised by chemiluminescence with luminol (Santa Cruz Biotechnologies, Heidelberg, Germany) and semi-quantified using ImageJ software (US National Institute of Health, Bethesda, MD, USA; http://imagej.nih.gov/ij/) with normalisation against $\beta$-actin (Sigma-Aldrich).

Cell viability and clonogenic assays. For determining viability, 5000 cells were seeded in 24-well plates for 7 days and stimulated as indicated in the different experiments. At the indicated time points, cells were harvested with trypsin, re-suspended in culture medium and counted using the Countess Automated Cell Counter (Invitrogen) following staining with Trypan blue dye.

For colony-formation assays, cells were seeded in six-well plates at a density of $5 \times 10^{3}$ cells per well in triplicate and treated as indicated in low-serum (2\%) medium for 7 days. Cells were fixed in $1 \%$ glutaraldehyde (Sigma-Aldrich) and stained with $2 \%$ crystal violet (Pro-Lab Diagnostics, Merseyside, UK). Images of plates were acquired with a desktop scanner (600 d.p.i.) and analysed with ImageJ software. The plating efficiency was calculated by dividing the number of colonies by the original seeding density. The surviving fraction was determined by comparing the plating efficiency of treated $v s$ control wells. The total colony area was calculated for each biological replicate by averaging the area of all colonies in replicate wells. Representative images of single colonies were acquired by bright-field microscopy.

Cell invasion and apoptosis assays. Cells were seeded at a density of $2.5 \times 10^{4}$ cells in the upper compartment of Matrigel-coated inserts $(8-\mu \mathrm{m}$ pore size; BioCoat, BD Biosciences, ErembodegemDorp, Belgium) or non-Matrigel-coated control inserts in serumfree medium. Fibroblast-conditioned medium was used as chemoattractant in the lower chamber. After $48 \mathrm{~h}$ of incubation, non-migrated cells in the upper chamber were removed from the upper surface of the filters with a PBS-soaked cotton swab. This was followed by fixation using $1 \%$ glutaraldehyde and staining with $0.1 \%$ crystal violet. Cells fixed on the lower face of the chambers were counted under a light microscope at a magnification of $\times 10$, averaging five random fields per insert.

To detect apoptosis, cells were stimulated as indicated in six-well plates, and oligonucleosomes were measured by ELISA (Roche). Apoptosis was also evaluated by immunoblotting for cleaved PARP1 (Fisher Scientific, Dublin, Ireland). 
Antibody-dependent cell-mediated cytotoxicity. Immune effector functions elicited by the monoclonal antibody D1(A12) were measured as previously described (Collins et al, 2012) using peripheral blood mononuclear cells (PBMCs). Approval for obtaining voluntary blood samples was granted by St Vincent's University Hospital Ethics Committee. Peripheral blood mononuclear cells were isolated from blood using Ficoll-Paque PLUS (GE Healthcare, Chalfont, UK). Antibody-dependent cell-mediated cytoxicity (ADCC) was determined using the Guava Cell Toxicity Kit (Millipore, Carrigtwohill, Cork, Ireland), according to the manufacturer's instructions. Percentage of cell death was determined on a Guava Easycyte flow cytometer using Cytosoft software (Millipore). K562 leukaemia cells were used as the positive control target cells for PBMC cell activity. Cetuximab was used as positive control antibody.

3D cell culture and spheroid assay. For three-dimensional (3D) cultures, $5 \times 10^{5}$ cells were seeded in Alvetex scaffolds (Reinnervate, Sedgefield, Co. Durham, UK) in low serum (2\%) medium and cultured for 7 days. Scaffolds were stained with a $0.25 \%$ solution of neutral red (Sigma-Aldrich) in PBS for $5 \mathrm{~min}$ at room temperature and imaged on a bright-field microscope at $\times 4$ magnification, averaging four random fields for each scaffold. A $\times 1$ magnification image of the entire scaffold was acquired with a standard digital camera. Neutral red staining was quantified with ImageJ software. Representative scaffolds were fixed in $4 \%$ paraformaldehyde for $18 \mathrm{~h}$ at $4{ }^{\circ} \mathrm{C}$, dehydrated with sequential ethanol washes (30-95\%), sliced into four quarters and embedded on edge in paraffin. Scaffolds were sectioned at $4 \mu \mathrm{m}$, deparaffinised using xylene and then stained using the standard haematoxylin (Harris modified; VWR International Ltd, Dublin, Ireland) and eosin (aqueous 1\%; Leica Biosystems Surgipath, Ashbourne, Ireland) technique.

Spheroid assays were performed with the $3 \mathrm{D}$ on-top protocol (Lee et al, 2007). Briefly, $4 \times 10^{4}$ cells were pre-incubated with the indicated treatments for $1 \mathrm{~h}$, seeded on Matrigel (BD Biosciences) and allowed to grow for 7 days in low-serum medium containing $10 \%$ Matrigel. Spheroid growth was monitored every $24 \mathrm{~h}$ and quantified at the end of 7 days by incubating spheroids with medium containing $40 \mu \mathrm{g} \mathrm{ml}^{-1}$ neutral red and quantifying staining intensity using ImageJ.

Immunofluorescence. Cells were seeded in eight-chamber glass slides (BD Biosciences) until subconfluent and stimulated as indicated in serum-free medium. Cells were fixed in $4 \%$ paraformaldehyde, permeabilized where indicated in $0.1 \%$ Triton and incubated $\mathrm{O} / \mathrm{N}$ with anti-ADAM-17 antibody (Abcam) followed by a Cy2-conjugated anti-mouse antibody (Jackson ImmunoResearch, Suffolk, UK) with DAPI (Dako, Glostrup,
Denmark) and Oregon-Green Phalloidin (Invitrogen) counterstains. Images were acquired with a LSM 510 confocal microscope (Zeiss, Cambridge, UK).

Statistical analysis. Statistical analysis of the data was performed using unpaired Student's $t$-test for differences between experimental group mean values. All $P$-values are two-tailed and considered statistically significant if $P<0.05$. All analyses were performed with Prism (GraphPad Software, La Jolla, CA, USA).

\section{RESULTS}

Effects of D1(A12) on ADAM-17 catalytic activity. One of the best-characterized functions of ADAM-17 is release of the EGFR ligand, TGF $\alpha$. Consequently, measurement of extracellular TGF $\alpha$ is widely used as a bioassay for ADAM-17 catalytic activity (Kenny and Bissell, 2007; Fridman et al, 2007a; Giricz et al, 2013; McGowan et al, 2013). Indeed, TGF $\alpha$ is the main EGFR ligand formed by TNBCs (Giricz et al, 2013). In order to identify suitable cell lines for studying the effects of D1(A12) on TGF $\alpha$ release, we initially investigated both basal and PMA-stimulated release of this ligand in a panel of seven TNBC cell lines. As shown in Figure 1A, only two out of the seven cell lines analysed, that is, HCC1937 and HCC1143, released high levels of TGF $\alpha$ following PMA stimulation. These two cell lines were then used to investigate a potential anticancer effect for D1(A12).

As shown in Figure 1B and C, D1(A12) significantly reduced the shedding of TGF $\alpha$ in HCC1143 $(-17.6 \%, P=0.003)$ and HCC1937 ( $-27.7 \%, P=0.009)$ cells. As a proof of concept, a commercial polyclonal antibody against the catalytic domain of ADAM-17 (abbreviated here as Ab17) also reduced TGF $\alpha$ shedding in both HCC1143 $(-36.3 \%, P=0.0004)$ and HCC1937 $(-54.2 \%, P=0.0015)$ cells. In contrast, both trastuzumab (which binds to HER2) and a non-specific IgG had no effect on levels of $\mathrm{TGF} \alpha$ released. In agreement with our previous results (McGowan et al, 2013), the low-molecular-weight and selective ADAM-17 inhibitor PF-548 (used as positive control) also reduced PMAinduced TGF $\alpha$ levels in HCC1143 $(-83.6 \%, P<0.0001)$ and HCC1937 ( $-74 \%, P=0.0124$ ) cells (Figure 1B and C). Increasing the concentration of $\mathrm{D} 1(\mathrm{~A} 12)$ by 5 - or 10 -fold did not result in a further reduction of $\mathrm{TGF} \alpha$ shedding (Supplementary Figure 1A and $\mathrm{B}$ ). This finding suggests the presence of a residual active pool of ADAM-17 that cannot be targeted by the antibody. Indeed, confocal microscopy analysis confirmed the presence of ADAM-17 in both intracellular and membrane-localized pools in basal condition and upon PMA-induced activation (Supplementary Figure 1C).
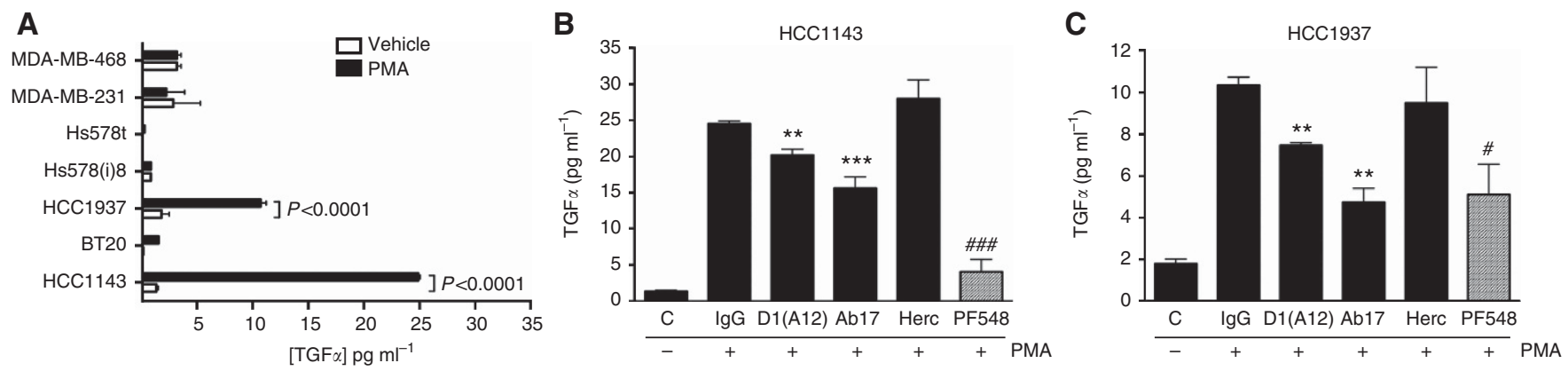

Figure 1. Effect of D1(A12) on shedding of the ADAM-17 substrate TGF $\alpha$. (A) Release of TGF $\alpha$ into the culture medium of seven triple-negative cell lines was measured by ELISA $1 \mathrm{~h}$ after stimulation with PMA (1 $\mu \mathrm{M})$ or DMSO control. Inhibition of PMA-induced TGF $\alpha$ shedding was measured in HCC1143 (B) or in HCC1937 (C) after $1 \mathrm{~h}$ pre-treatment with D1(A12) (200 nM), Ab17 (0.5 $\left.\mu \mathrm{g} \mathrm{ml}^{-1}\right)$, trastuzumab (Herc) (20 $\left.\mu \mathrm{g} \mathrm{ml}{ }^{-1}\right), \mathrm{PF}-548$ $(5 \mu \mathrm{M})$ and corresponding $\mathrm{lgG}$ or DMSO controls. Data are mean values \pm s.e.m. of three independent experiments. ${ }^{\star \star} P<0.001,{ }^{\star \star \star} P<0.0001$ compared with IgG control; ${ }^{\#}<0.005,{ }^{\# \# \#} P<0.0001$ compared with DMSO control (Student's t-test). 
Effects of D1(A12) on cell viability. As clonogenic cell growth assays are considered to be among the best initial preclinical assays for evaluating drug cytotoxicity (Weisenthal et al, 1983), we first used this technique to investigate the effects of D1(A12) on cell viability. Consistent with the decreased release of soluble TGF $\alpha$, the addition of $\mathrm{D} 1(\mathrm{~A} 12)$ reduced clonogenic potential. However, the effects of D1(A12) were cell line dependent. Thus, with HCC1937, the monoclonal antibody reduced both the number of colonies ( $-14.9 \%, P=0.0002$; Figure $2 \mathrm{~A}$ ) and the total colony area $(-15.5 \%, P<0.0001$; Figure 2B). However, with HCC1143 cells, $\mathrm{D} 1$ (A12) reduced the total colony area $(-20.4 \%, P=0.005$; Figure $3 \mathrm{~A}$ ) but had no effect on colony number (Figure $3 \mathrm{~B}$ ). By contrast, the polyclonal antibody, Ab17, reduced the colony number in both HCC1937 ( $-36.2 \%, P=0.005$; Figure 2A) and HCC1143 ( $-25.3 \%, P=0.029$; Figure 3B) cells. Similarly, Ab17 also reduced the total colony area in both HCC1937 $(-20.7 \%$, $P=0.029$; Figure 2B) and HCC1143 $(-18.3 \%, P=0.0004$; Figure 3B) cells. PF-548 showed similar effects, reducing the colony number and total colony area in both cell lines (Figures 2A, B, 3A and B).

Reduction in cell growth by $\mathrm{D} 1(\mathrm{~A} 12)$ and Ab17 in twodimensional monolayers was confirmed by direct counting of cells: $\mathrm{D} 1$ (A12) reduced cell proliferation by 3.3 -fold $(P<0.0001)$ for HCC1143 and 1.5-fold $(P=0.013)$ for HCC1937 cells and Ab17 reduced proliferation by 4.3 -fold $(P<0.0001)$ for HCC1143 and 2.1-fold ( $P=0.0006)$ for HCC1937 cells; Figures 2C and 3C). As a negative control, we used the Hs578t cell line, which was unresponsive in our initial TGF $\alpha$-shedding assay (Figure 1A). Neither D1(A12) or Ab17 reduced clonogenic potential (Supplementary Figure 2A and B) or cell proliferation (Supplementary Figure 2C) in this cell line. PF-548 also lacked an inhibitory effect on Hs578t cells, confirming previously published results (McGowan et al, 2013).

In order to investigate the effects of $\mathrm{D} 1(\mathrm{~A} 12)$ in a more biologically relevant model (Breslin and O’Driscoll, 2013), we used two models of 3D in vitro cell culture. First, we used a cross-linked polystyrene-based scaffold with a thickness of $200 \mu \mathrm{m}$ and pore sizes of $\sim 40 \mu \mathrm{m}$, which enables exchange of nutrients, gases and waste products by passive diffusion, and promotes cell growth in tissue-like structures (Maltman and Przyborski, 2010). Using this system, D1(A12) was also found to reduce cell growth of both HCC1143 ( $-55.7 \%, P=0.02$; Figure 4A) and HCC1937 cells $(-73.3 \%, P=0.01$; Figure $4 \mathrm{~B})$. The structure of cells cultured in this system is illustrated in $\mathrm{H} \& \mathrm{E}$ staining of representative scaffolds (Supplementary Figure $3 \mathrm{~A}$ and $\mathrm{B}$ ). We then cultured cells into spheroids in extracellular matrix using the 3D on-top assay (Lee et al, 2007). Growth of HCC1937 colonies was reduced by $21.4 \%$ in the presence of D1(A12) $(P=0.0013$; Figure $4 \mathrm{C})$, and that of HCC1143 colonies was reduced by $35.8 \%(P=0.0006$; Figure $4 \mathrm{D})$, compared with IgG control.
A

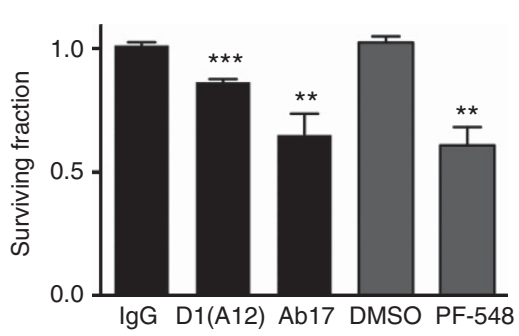

B

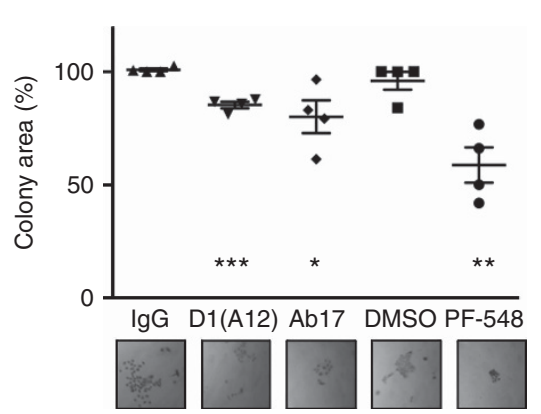

C

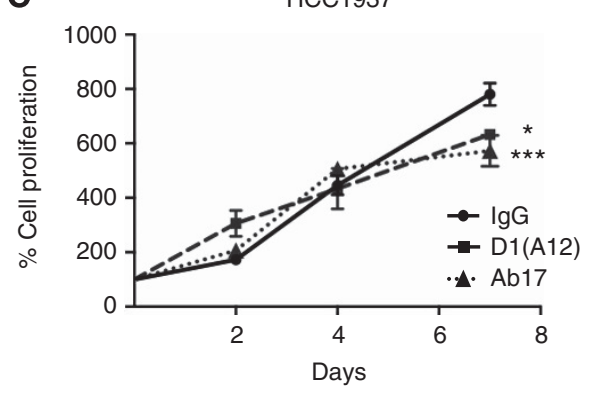

Figure 2. Cell growth and clonogenic survival of HCC1937 breast cancer cell line. Cells were seeded and grown for 7 days in the presence of PF-548 (5 $\mu \mathrm{M})$, D1(A12) (200 nM), Ab17 $\left(0.5 \mu \mathrm{g} \mathrm{ml}^{-1}\right)$ or corresponding vehicle controls. (A) Colonies formed by individual cells were stained and counted. (B) The total colony area was also calculated for each biological replicate, and representative images of single colonies are included. ${ }^{\star} P<0.05,{ }^{\star \star} P<0.001$ and ${ }^{* \star \star} P<0.0001$ compared with vehicle control (Student's $t$-test). (C) Live cells were counted at three different time points with Trypan blue stain. Percentage cell growth compared with initial seeding density is reported. ${ }^{\star} P<0.05$, ${ }^{\star \star \star} P<0.0001$ compared with IgG at corresponding time point (two-way ANOVA).

A

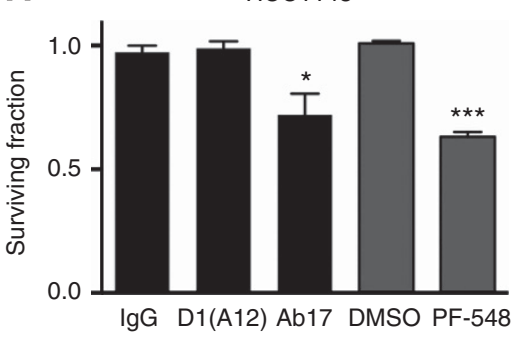

B

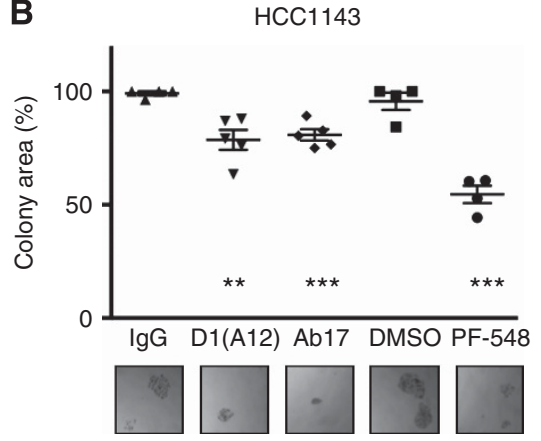

C

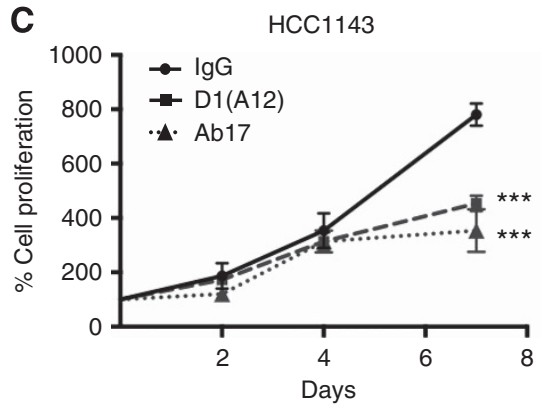

Figure 3. Cell growth and clonogenic survival of HCC1143 breast cancer cell line. Cells were seeded and grown for 7 days in the presence of PF-548 (5 $\mu \mathrm{M}), \mathrm{D} 1(\mathrm{~A} 12)(200 \mathrm{~nm}), \mathrm{Ab} 17\left(0.5 \mu \mathrm{g} \mathrm{ml}^{-1}\right)$ or corresponding vehicle controls. (A) Colonies formed by individual cells were stained and counted. (B) The total colony area was also calculated for each biological replicate, and representative images of single colonies are included. ${ }^{\star} P<0.05,{ }^{* \star} P<0.001$ and ${ }^{* \star \star} P<0.0001$ compared with vehicle control (Student's $t$-test). (C) Live cells were counted at three different time points with Trypan blue stain. Percentage cell growth compared with initial seeding density is reported. ${ }^{\star \star \star} P<0.0001$ compared with IgG at corresponding time point (two-way ANOVA). 
A
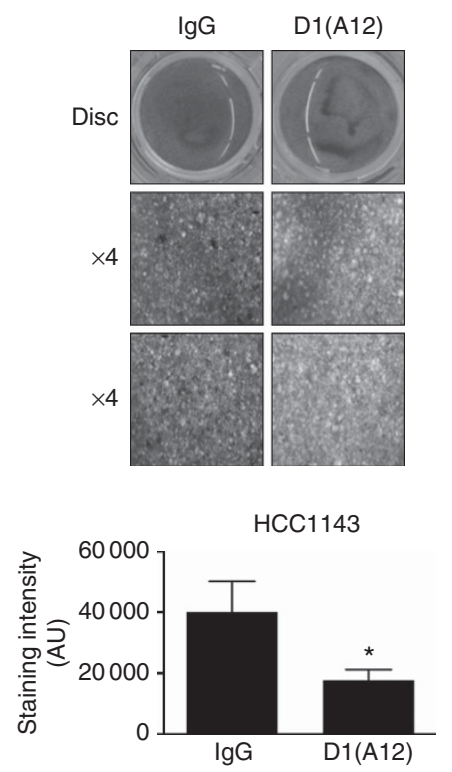

B
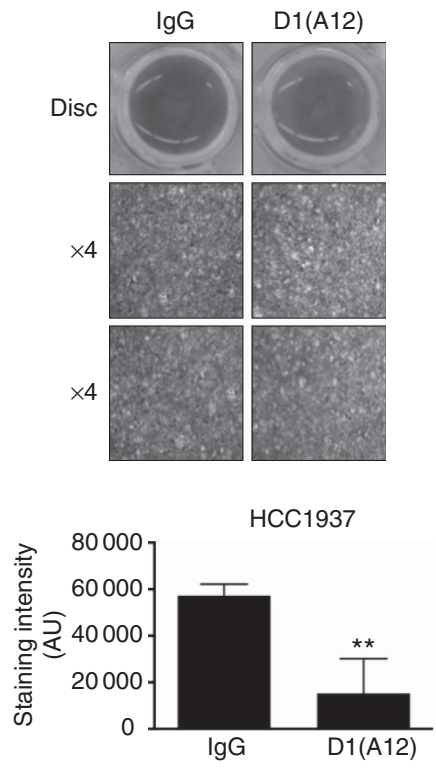

C $\quad \mathrm{HCC} 1937$

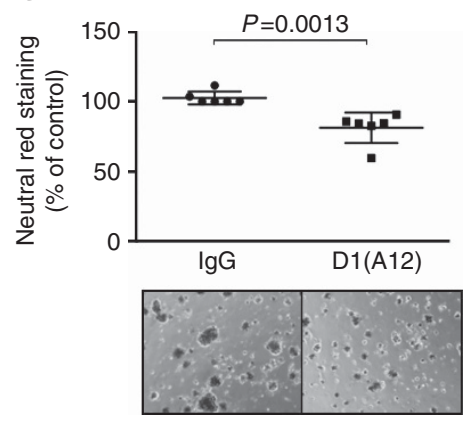

D

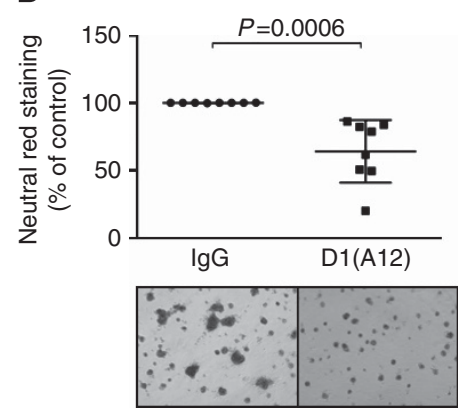

Figure 4. Effects of D1(A12) on in vitro 3D cell culture. HCC1143 (A) and HCC1937 (B) cells were cultured on Alvetex scaffolds for 7 days in the presence of IgG or D1(A12) (200 nM). Cells were stained with $0.25 \%$ neutral red, and scaffolds were photographed. Whole-scaffold image and two representative fields at $\times 4$ magnification are shown, along with the mean staining intensity of three different experiments. ${ }^{\star} P<0.05$ and ${ }^{\star \star} P<0.001$ compared with IgG control (Student's t-test). HCC1937 (C) and HCC1143 (D) cells were cultured on Matrigel with the 3D on-top assay for 7 days in the presence of IgG or D1(A12) $(200 \mathrm{~nm})$ and stained with neutral red. Representative images are shown with the mean staining intensity of three different experiments. A full color version of this figure is available at British Journal of Cancer journal online.

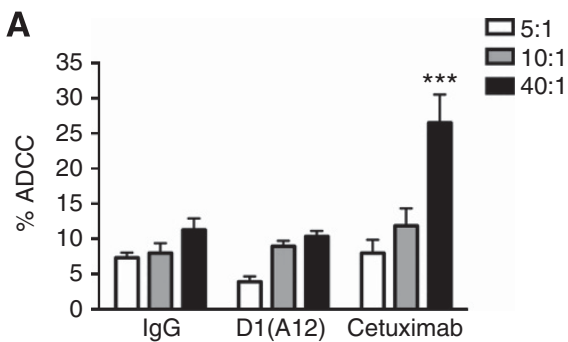

C

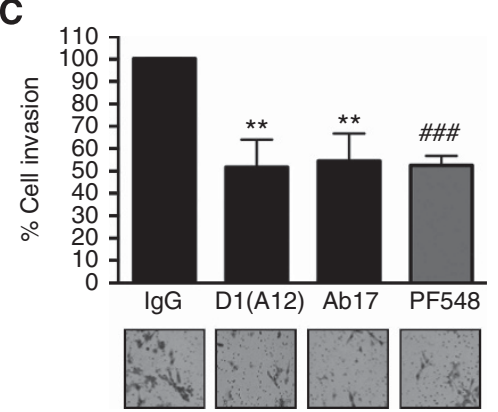

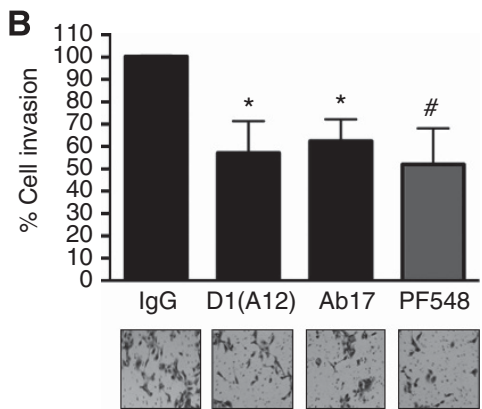

D

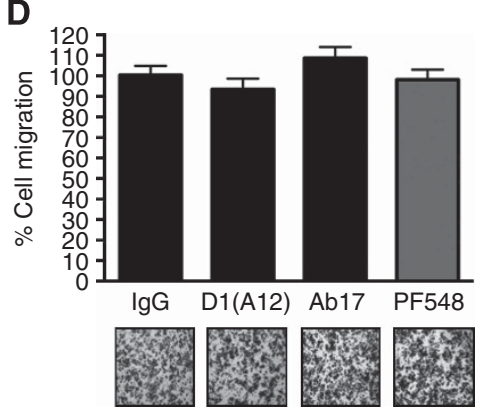

Figure 5. Effects of D1(A12) on ADCC and cell motility. (A) Lysis of HCC1937 target cells was determined using PBMC effector cells. Three different ratios of effector:target cells were used (5:1, 10:1 and 40:1). Percentage ADCC was calculated after $4 \mathrm{~h}$ incubation with either lgG, $200 \mathrm{~nm}$ D1(A12) or $200 \mathrm{~nm}$ cetuximab for each ratio as indicated, in triplicate experiments. ${ }^{\star \star \star} P<0.0001$ compared with lgG control at corresponding ratio (two-way ANOVA). (B) HCC1937 cells were cultured in Matrigel-coated Boyden chambers using fibroblast-conditioned media as a chemoattractant. Cells were treated with IgG control, D1(A12) $(200 \mathrm{nM})$, Ab17 (0.5 $\left.\mu \mathrm{g} \mathrm{ml}^{-1}\right)$, PF-548 (5 $\left.\mu \mathrm{M}\right)$ or DMSO control for $72 \mathrm{~h}$, then invaded cells were fixed, stained and counted. (C) HCC1143 and (D) Hs578t cells were treated as above and cultured in control Boyden chambers without Matrigel coating. Representative images are shown with mean \pm s.e.m. values of four experiments. ${ }^{*} P<0.05,{ }^{*} P<0.001$ compared to

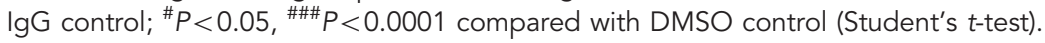


As certain anticancer therapeutic antibodies such as trastuzumab (Clynes et al, 2000) and cetuximab (Roberti et al, 2011) exert their cytotoxicity, in part, by inducing ADCC, we investigated whether D1(A12) acted by this mechanism. Using three different ratios of PBMCs to HCC1937 cells (5:1, 10:1 and 40:1), no ADCC activity was observed with D1(A12) (Figure 5A). In contrast, the EGFR targeting antibody, cetuximab, which was previously found to induce ADCC response in breast cancer cells (Roberti et al, 2011), increased cytotoxicity at a 40:1 ratio of PBMC to HCC1937 cells. Similar results to HCC1937 cells were also obtained with HCC1143 cells (data not shown).

Effects of D1(A12) on cell migration and invasion. Treatment of HCC1937 cells with either D1(A12) or Ab17 significantly reduced cell invasion through an extracellular matrix by $43.2 \%(P=0.038)$ and $37.9 \%(P=0.017)$, respectively (Figure 5B). As HCC1143 cells were not invasive under basal condition, the effects of the antibodies could not be investigated on this end point. However, both $\mathrm{D} 1(\mathrm{~A} 12)$ and Ab17 significantly reduced cell migration in HCC1143 cells by $48.5 \%(P=0.008)$ and $45.8 \%(P=0.009)$, respectively (Figure 5C). PF-548 also showed similar effects, reducing HCC1937 cell invasion by $48.3 \%(P=0.04$; Figure $5 \mathrm{~B})$ and HCC1143 cell migration by $46.7 \%(P<0.0001$; Figure $5 C)$. In contrast, cell migration was not affected by either D1(A12), Ab17 or PF-548 (Figure 5D) in the negative control cell line Hs578t.

Effects of D1(A12) on apoptosis. As D1(A12) affected cell viability, we investigated its effect on cell death. Using HCC1143 cells, D1(A12) induced a 2.73-fold increased expression $(P=0.034)$ and 0.34 -fold increased cleavage $(P=0.0152)$ of the caspase- 3 substrate PARP1 (Ha and Snyder, 1999) (Figure 6A). In addition, $\mathrm{D} 1(\mathrm{~A} 12)$ induced a $23.1 \%$ increase in fragmented DNA $(P=0.0012$; Figure 6B). These findings, when taken together, suggest that D1(A12) increased apoptosis. Similarly, Ab17 increased the expression $(+0.31$-fold, $P=0.036)$ and cleavage $(+9.3$-fold, $P=0.009$ ) of PARP1 (Figure $6 \mathrm{~A}$ ), and also induced a $22 \%$ increase in the concentration of fragmented DNA $(P=0.012$; Figure 6B), again suggesting that this antibody induces apoptosis. Similarly, when HCC1143 cells were cultured in 3D conditions using the polystyrene scaffolds, D1(A12) also induced a $27.2 \%$ increase in DNA fragmentation $(P=0.0033$; Figure 6C).

Effect of D1(A12) on intracellular signalling. Having shown a reduction in TGF $\alpha$ shedding, we investigated whether D1(A12) impacted on activation of EGFR and downstream signalling. Consistent with increased TGF $\alpha$ release (Figure 1), $1 \mathrm{~h}$ of treatment with PMA induced EGFR phosphorylation, which was inhibited by D1(A12) pre-treatment $(P=0.00276$; Figure $7 \mathrm{~A})$. In addition, basal levels of EGFR phosphorylation were significantly reduced by longterm $(24 \mathrm{~h})$ treatment with either D1(A12) $(P=0.0119)$ or Ab17 $(P=0.0041$; Figure7B), consistent with the previously reported reduction in phosphorylated EGFR by PF-548 (McGowan et al, 2013).

To investigate whether pro-tumorigenic cell signalling downstream of EGFR was also affected by ADAM-17 inhibition, we treated HCC1937 cells with PMA for $6 \mathrm{~h}$. The observed increased phosphorylation of ERK1/2 MAPK, AKT and mTOR was reduced by pre-treatment with either D1(A12) and Ab17 (Figure 7C). Furthermore, analysis of a longer time course $(24 \mathrm{~h}$ after PMA treatment) revealed that activation of ERK1/2 was sustained, while activation of AKT was transient, which resulted in sustained mTOR activation (Supplementary Figure 4A). Sustained activation of both ERK1/2 and mTOR after $24 \mathrm{~h}$ of PMA treatment was also decreased by pre-treatment with either D1(A12) or Ab17.

\section{DISCUSSION}

As mentioned in the Introduction section above, in contrast to the intensive ongoing research into targeting HER proteins and their downstream signalling proteins, relatively little work to date has focused on potential upstream targets. Here we show that targeting ADAM-17, which is responsible for the release of multiple EGFR ligands (Sahin et al, 2004; Sahin and Blobel, 2007), with a monoclonal antibody, decreased cell viability, cell motility and enhanced cell death in two TNBC cell lines. Our results are thus in agreement with Richards et al (2012), who reported that D1(A12) reduced tumour growth in an ovarian cancer model system.

Unlike widely used therapeutic monoclonal antibodies such as trastuzumab and cetuximab, which exert part of their anticancer
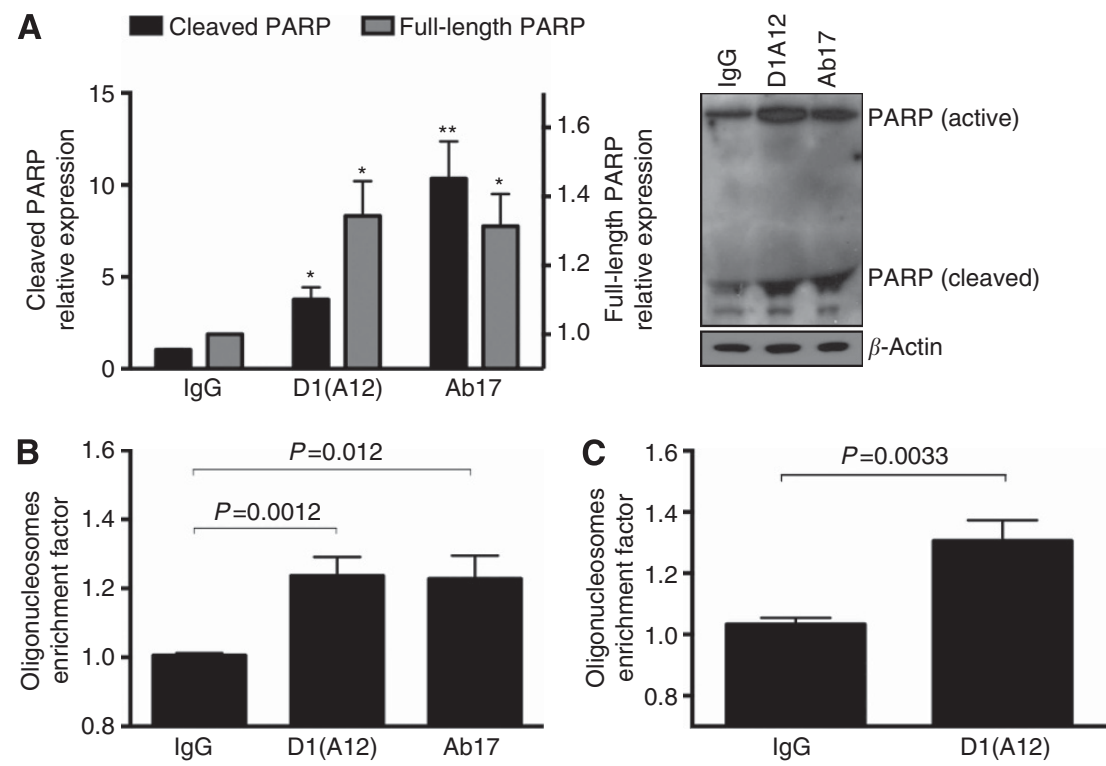

Figure 6. Effects of D1(A12) on cell death of HCC1143 breast cancer cells. Cells were treated for $48 \mathrm{~h}$ with lgG control, D1(A12) (200 nM) or Ab17 $\left(0.5 \mu \mathrm{g} \mathrm{ml}^{-1}\right)$. (A) Cell lysates were blotted with a PARP antibody and the relative amount of full-length and cleaved PARP was measured using $\beta$-actin as a loading control. A representative blot is shown with the mean densitometric analysis of four experiments. ${ }^{\star} P<0.05, \star \star P<0.001$ compared with IgG control. Oligonucleosomes were measured by ELISA from (B) cell lysates and (C) cell culture supernatants from 3D scaffolds. 
A
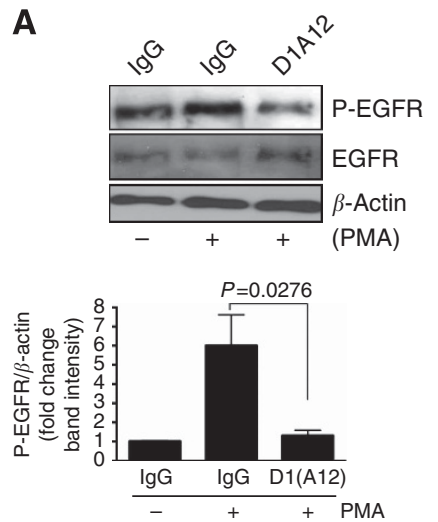

B
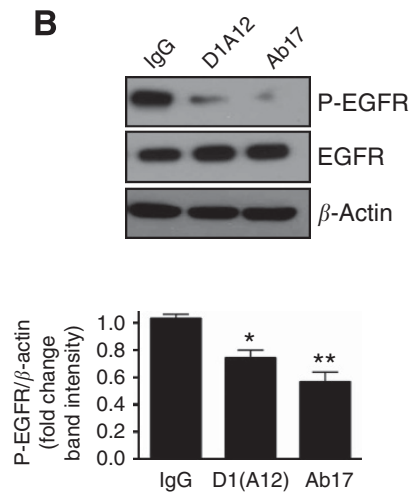

C

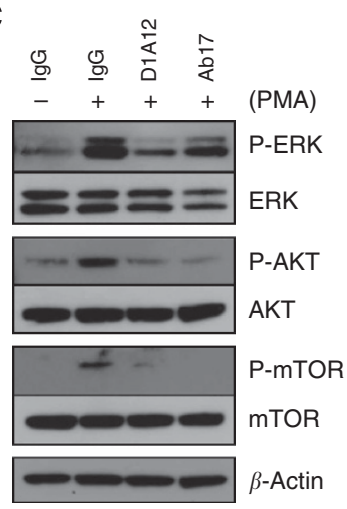

Figure 7. Effects of D1(A12) on cell signalling. (A) HCC1937 cells were pre-incubated for $1 \mathrm{~h}$ with lgG or D1(A12) (200 nM) before $1 \mathrm{~h}$ treatment with PMA $(1 \mu \mathrm{M})$. Cell lysates were blotted for P-EGFR, total EGFR and $\beta$-actin. A representative western blot is shown together with the mean densitometric analysis of three different experiments. (B) Cells were treated with IgG, $200 \mathrm{~nm}$ D1(A12) or $0.5 \mu \mathrm{g} \mathrm{ml}^{-1} \mathrm{Ab} 17 \mathrm{for} 24 \mathrm{~h}$, lysed and blotted as described above. Levels of P-EGFR were normalised to $\beta$-actin, and the mean \pm s.e.m. of three independent experiments reported. ${ }^{\star} P<0.05,{ }^{*} P<0.001$ compared with IgG control (Student's t-test). (C) HCC1937 cells were pre-treated for $1 \mathrm{~h}$ with IgG, 200 nM D1(A12) or $0.5 \mu \mathrm{g} \mathrm{ml}^{-1} \mathrm{Ab} 17$, then treated for $6 \mathrm{~h}$ with $1 \mu \mathrm{M}$ PMA or vehicle control. Cell lysates were blotted with the indicated antibodies. A representative blot is shown.

activity by inducing ADCC (Collins et al, 2012), D1(A12) lacked such activity at least in the two cell lines investigated in this study. Our results thus suggest that the anti-proliferative effects of D1(A12) are exerted directly via inhibition of ADAM-17. In addition to blocking cell growth, D1(A12) increased cell death, at least in HCC1143 cells.

Overall, we found broadly similar effects with D1(A12), a commercial polyclonal antibody reactive against the active site of ADAM-17 (Ab17), and the selective low-molecular-weight inhibitor against ADAM-17 (PF-548). Some differences, however, were found with the three anti-ADAM-17 agents used in this study. Thus, in HCC1143 cells, while D1(A12) decreased total colony area, both the commercial ADAM-17 antibody and PF-548 decreased colony numbers, as well as colony area. This finding suggests that the ADAM-17 antibodies and PF-548 may not act identically on cell growth, possibly relating to the broader specificity of the polyclonal antibody and the low-molecularweight agent, compared with the more likely specific action of D1(A12).

In some experiments, the three agents also differed in the intensity of their inhibitory effects. Specifically, PF-548 had increased potency as opposed to D1(A12) in inhibiting TGF $\alpha$ shedding and clonogenic cell survival. This is also likely to be related to differences in specificity between low-molecular-weight inhibitors and monoclonal antibodies. At the concentration used in this study, PF-548 has been reported to inhibit ADAM-10 and other MMPs, although with reduced affinity compared with ADAM-17 (Zhang et al, 2004).

A further possible explanation for the reduced potency of D1(A12) compared with PF-548 may relate to the cellular localisation of active ADAM-17. Thus, ADAM-17 has been reported to be located in the endoplasmic reticulum and in perinuclear secretory vesicles, as well as at the cell membrane, with membrane localisation increasing transiently after activation by phorbol esters before internalisation and recycling (Murphy, 2008). Our data confirm this dual membrane-cytoplasmic location of ADAM-17. Although ADAM-17 at the cell membrane should be accessible for antibody binding, it is unclear whether the same is true for the intracellular form. However, the intracellular ADAM17 pool is unlikely to be targeted by $\mathrm{D} 1$ (A12), which could explain the reduced potency of D1(A12) compared with PF-548, as well as the failure to increase potency in terms of TGF $\alpha$ shedding with increasing concentration of D1(A12).
In addition to the differences found with the various antiADAM-17 agents used, some of the observed effects were found to vary between the two cell lines used. Thus, with HCC1937 cells, $\mathrm{D} 1(\mathrm{~A} 12)$ reduced both colony number and total colony area, whereas with HCC1143 cells, the number of colonies was unaffected but area was reduced. The reason(s) for these differences is unclear but may relate to different signalling systems in the two cell lines investigated, which express different baseline levels of TGF $\alpha$ and active ADAM-17 (McGowan et al, 2013). Possible differences in HER ligand profiles and expression of other MMPs could also account for some of the different responses, for example, through activation of compensatory mechanisms (Le Gall et al, 2009).

In this preclinical study, our primary focus was on TNBC cell lines, as patients with this form of breast cancer currently lack a validated targeted therapy (Duffy et al, 2012). Indeed, some recent findings suggest that ADAM-17 may have a particularly important role in this molecular subtype of breast cancer. Thus, using extracts of breast cancer, we have previously shown that levels of ADAM17 , including the active form, were increased in TN compared with non-TN (McGowan et al, 2013). Similarly, in breast cancer cell lines, ADAM-17 was found to be more highly expressed in TN than in cells from other molecular forms of breast cancer (Giricz et al, 2013). Furthermore, inhibition of ADAM-17 with lowmolecular-weight inhibitors was found to decrease growth, migration and invasion in a number of different TNBC cell lines (Giricz et al, 2013; McGowan et al, 2013). These effects of ADAM17 inhibition are likely to be owing, at least in part, to blockage of TGF $\alpha$ release (Giricz et al, 2013; McGowan et al, 2013), which in turn results in decreased EGFR signalling.

Possibly related to the increased levels of ADAM-17 in TNBC, there is substantial evidence that EGFR signalling is more important in this molecular subform than in other subforms of breast cancer (Duffy et al, 2012). Indeed, in a recent study (Dutta et al, 2012), EGFR was identified as a key hub gene driving the growth of TNBC. Unlike the situation in certain cancers such as non-small cell lung malignancy where EGFR can be activated by mutation (Soria et al, 2012), EGFR mutations are rare in breast cancer (Banerji et al, 2012; Cancer Genome Atlas Network, 2012). Thus, the main mechanism of EGFR signal activation in breast cancer is likely to be mediated by ADAM-17catalysed release of ligands such as TGF $\alpha$. Thus, inhibition of ADAM-17 might therefore be expected to decrease EGFR 
homodimeric signalling, as well as signalling from the EGFR-HER2 and EGFR-HER3 complexes.

Despite the promising preclinical data, to our knowledge, a selective ADAM-17 inhibitor has not undergone testing in clinical trials, although a dual ADAM-10/ADAM-17 inhibitor has been evaluated in an early-phase trial in patients with HER2-positive advanced breast cancer (Infante et al, 2007; Fridman et al, 2007b). Results from these early phase trials showed that this drug was well tolerated (Infante et al, 2007). In particular, musculoskeletal side effects (which were previously found with matrix metalloproteinase inhibitors) or anti-EGFR-related side effects, such as skin rash, were not observed. Furthermore, there was no evidence of increased release of liver enzymes, bone marrow toxicity or increase in cardiomyopathy (Infante et al, 2007; Fridman et al, 2007b).

Consistent with these clinical trial results are studies on humans with an inherited deficiency of ADAM-17. Recently, such a family was identified (Blaydon et al, 2011), with two affected members presenting with a homozygous deletion mutation in ADAM17 leading to a truncated protein that lacks all functional domains. In this family, the female member died at 12 years due to a parvovirus B19-associated myocarditis. The male, however, led a relatively normal life despite suffering from inflammatory bowel disease as well as several skin infections.

In conclusion, our cell line data, using several different end point assays, suggests that targeting ADAM-17 with the monoclonal antibody D1(A12) has anticancer activity in TNBC cell lines. Our findings, however, do not exclude the possibility that ADAM17 inhibition in non-TNBC cells will also have efficacy. The results reported here should now be confirmed in an appropriate animal model system. As the pharmacodynamics and pharmacokinetic of D1(A12) have been studied in a xenograft model of ovarian carcinoma (Richards et al, 2012), it should be relatively easy to translate our preclinical results into an in vivo model of TNBC. Although D1(A12) did not exhibit ADCC activity in our investigation, it might be expected to be a more specific inhibitor of ADAM17 than the low-molecular-weight inhibitor previously reported (McGowan et al, 2013), and thus have fewer side effects in patients.

\section{ACKNOWLEDGEMENTS}

The funding for this study is acknowledged in part from Science Foundation Ireland, Strategic Research Cluster Award (08/SRC/ B1410) to Molecular Therapeutics for Cancer Ireland/National Cancer Research Centre of Ireland and in part from the BREASTPREDICT Collaborative Cancer Research Centre programme (CCRC113GAL) of the Irish Cancer Society. In addition, PMMcG was funded by an Irish Cancer Society Research Fellowship (CRF11MCG). The opinions, findings and conclusions or recommendations expressed in this material, however, are those of the author and do not necessarily reflect the views of the funding organisations. GM and CJT are funded by Cancer Research UK. The technical expertise of Dr. Dimitri Sholz (UCD Conway Institute, Dublin) is also acknowledged.

\section{CONFLICT OF INTEREST}

The authors declare no conflict of interest.

\section{REFERENCES}

Banerji S, Cibulskis K, Rangel-Escareno C, Brown KK, Carter SL, Frederick AM, Lawrence MS, Sivachenko AY, Sougnez C, Zou L,
Cortes ML, Fernandez-Lopez JC, Peng S, Ardlie KG, Auclair D, Bautista-Piña V, Duke F, Francis J, Jung J, Maffuz-Aziz A, Onofrio RC, Parkin M, Pho NH, Quintanar-Jurado V, Ramos AH, Rebollar-Vega R, Rodriguez-Cuevas S, Romero-Cordoba SL, Schumacher SE, Stransky N, Thompson KM, Uribe-Figueroa L, Baselga J, Beroukhim R, Polyak K, Sgroi DC, Richardson AL, Jimenez-Sanchez G, Lander ES, Gabriel SB, Garraway LA, Golub TR, Melendez-Zajgla J, Toker A, Getz G, Hidalgo-Miranda A, Meyerson M (2012) Sequence analysis of mutations and translocations across breast cancer subtypes. Nature 486: 405-409.

Blaydon DC, Biancheri P, Di W-L, Plagnol V, Cabral RM, Brooke MA, van Heel DA, Ruschendorf F, Toynbee M, Walne A, O’Toole EA, Martin JE, Lindley K, Vulliamy T, Abrams DJ, MacDonald TT, Harper JI, Kelsell DP (2011) Inflammatory skin and bowel disease linked to ADAM17 deletion. $N$ Engl J Med 365: 1502-1508.

Borrell-Pagès M, Rojo F, Albanell J, Baselga J, Arribas J (2003) TACE is required for the activation of the EGFR by TGF- $\alpha$ in tumors. EMBO J 22: $1114-1124$

Breslin S, O’Driscoll L (2013) Three-dimensional cell culture: the missing link in drug discovery. Drug Discov Today 18: 240-249.

Caiazza F, Elliott L, David F, Sheahan K, Doherty GA, Ryan EJ (2015) Targeting EGFR in metastatic colorectal cancer beyond the limitations of KRAS status: alternative biomarkers and therapeutic strategies. Biomarkers in Medicine 9: 363-375.

Cancer Genome Atlas Network (2012) Comprehensive molecular portraits of human breast tumours. Nature 490: 61-70.

Clynes RA, Towers TL, Presta LG, Ravetch JV (2000) Inhibitory Fc receptors modulate in vivo cytotoxicity against tumor targets. Nat Med 6: 443-446.

Collins DM, O'Donovan N, McGowan PM, O'Sullivan F, Duffy MJ, Crown J (2012) Trastuzumab induces antibody-dependent cell-mediated cytotoxicity (ADCC) in HER-2-non-amplified breast cancer cell lines. Ann Oncol 23: 1788-1795.

Duffy MJ, McGowan PM, Crown J (2012) Targeted therapy for triple-negative breast cancer: Where are we? Int J Cancer 131: 2471-2477.

Duffy MJ, McKiernan E, O’Donovan N, McGowan PM (2009a) Role of ADAMs in cancer formation and progression. Clin Cancer Res 15: $1140-1144$.

Duffy MJ, McKiernan E, O'Donovan N, McGowan PM (2009b) The role of ADAMs in disease pathophysiology. Clin Chim Acta 403: 31-36.

Dutta B, Pusztai L, Qi Y, Andre F, Lazar V, Bianchini G, Ueno N, Agarwal R, Wang B, Shiang CY, Hortobagyi GN, Mills GB, Symmans WF, Balázsi G (2012) A network-based, integrative study to identify core biological pathways that drive breast cancer clinical subtypes. Br J Cancer 106: $1107-1116$.

Fridman JS, Caulder E, Hansbury M, Liu X, Yang G, Wang Q, Lo Y, Zhou B-B, Pan M, Thomas SM, Grandis JR, Zhuo J, Yao W, Newton RC, Friedman SM, Scherle PA, Vaddi K (2007a) Selective inhibition of ADAM metalloproteases as a novel approach for modulating ErbB pathways in cancer. Clin Cancer Res 13: 1892-1902.

Fridman JS, Scherle PA, Liu X (2007b) Preclinical characterization of INCB7839, a potent and selective inhibitor of ErbB ligand and HER2 receptor shedding: inhibition of ADAM10 and ADAM17 for the treatment of breast cancer. Cancer Res Treat 106: S82.

Giricz O, Calvo V, Peterson EA, Abouzeid CM, Kenny PA (2013) TACEdependent TGF $\alpha$ shedding drives triple-negative breast cancer cell invasion. Int J Cancer 133(11): 2587-2595.

Gooz M (2010) ADAM-17: the enzyme that does it all. Crit Rev Biochem Mol Biol 45: 146-169.

Ha HC, Snyder SH (1999) Poly(ADP-ribose) polymerase is a mediator of necrotic cell death by ATP depletion. Proc Natl Acad Sci USA 96: 13978-13982.

Heuckmann JM, Rauh D, Thomas RK (2012) Epidermal growth factor receptor (EGFR) signaling and covalent EGFR inhibition in lung cancer. $J$ Clin Oncol 30: 3417-3420.

Hughes L, Malone C, Chumsri S, Burger AM, McDonnell S (2008) Characterisation of breast cancer cell lines and establishment of a novel isogenic subclone to study migration, invasion and tumourigenicity. Clin Exp Metastasis 25: 549-557.

Infante J, Burris HA, Lewis N (2007) A multicenter phase Ib study of the safety, pharmacokinetics, biological activity and clinical efficacy of INCB7839, a potent and selective inhibitor of ADAM10 and ADAm17. Breast Cancer Res Treat 106: S269.

Jelovac D, Emens LA (2013) HER2-directed therapy for metastatic breast cancer. Oncology (Williston Park) 27: 166-175. 
Kenny PA, Bissell MJ (2007) Targeting TACE-dependent EGFR ligand shedding in breast cancer. J Clin Invest 117: 337-345.

Le Gall SM, Bobé P, Reiss K, Horiuchi K, Niu X-D, Lundell D, Gibb DR, Conrad D, Saftig P, Blobel CP (2009) ADAMs 10 and 17 represent differentially regulated components of a general shedding machinery for membrane proteins such as transforming growth factor alpha, L-selectin, and tumor necrosis factor alpha. Mol Biol Cell 20: 1785-1794.

Lee GY, Kenny PA, Lee EH, Bissell MJ (2007) Three-dimensional culture models of normal and malignant breast epithelial cells. Nat Methods 4: 359-365.

Ma X, Hu Y (2013) Targeting PI3K/Akt/mTOR cascade: the medicinal potential, updated research highlights and challenges ahead. Curr Med Chem 20(24): 2991-3010.

Maltman DJ, Przyborski SA (2010) Developments in three-dimensional cell culture technology aimed at improving the accuracy of in vitro analyses. Biochem Soc Trans 38: 1072-1075.

McGowan PM, McKiernan E, Bolster F, Ryan BM, Hill ADK, McDermott EW, Evoy D, O’Higgins N, Crown J, Duffy MJ (2008) ADAM-17 predicts adverse outcome in patients with breast cancer. Ann Oncol 19 : 1075-1081.

McGowan PM, Mullooly M, Caiazza F, Sukor S, Madden SF, Maguire AA, Pierce A, McDermott EW, Crown J, O'Donovan N, Duffy MJ (2013) ADAM-17: a novel therapeutic target for triple negative breast cancer. Ann Oncol 24: 362-369.

McGowan PM, Ryan BM, Hill ADK, McDermott E, O’Higgins N, Duffy MJ (2007) ADAM-17 expression in breast cancer correlates with variables of tumor progression. Clin Cancer Res 13: 2335-2343.

Murphy G (2008) The ADAMs: signalling scissors in the tumour microenvironment. Nat Rev Cancer 8: 932-941.

Ocaña A, Amir E, Seruga B, Martin M, Pandiella A (2013) The evolving landscape of protein kinases in breast cancer: clinical implications. Cancer Treat Rev 39: 68-76.
Richards FM, Tape CJ, Jodrell DI, Murphy G (2012) Anti-tumour effects of a specific anti-ADAM17 antibody in an ovarian cancer model in vivo. PLoS ONE 7: e40597.

Roberti MP, Barrio MM, Bravo AI, Rocca YS, Arriaga JM, Bianchini M, Mordoh J, Levy EM (2011) IL-15 and IL-2 increase Cetuximab-mediated cellular cytotoxicity against triple negative breast cancer cell lines expressing EGFR. Breast Cancer Res Treat 130: 465-475.

Sahin U, Blobel CP (2007) Ectodomain shedding of the EGF-receptor ligand epigen is mediated by ADAM17. FEBS Lett 581: 41-44.

Sahin U, Weskamp G, Kelly K, Zhou H-M, Higashiyama S, Peschon J, Hartmann D, Saftig P, Blobel CP (2004) Distinct roles for ADAM10 and ADAM17 in ectodomain shedding of six EGFR ligands. J Cell Biol 164: 769-779.

Soria J-C, Mok TS, Cappuzzo F, Jänne PA (2012) EGFR-mutated oncogeneaddicted non-small cell lung cancer: current trends and future prospects. Cancer Treat Rev 38: 416-430.

Tape CJ, Willems SH, Dombernowsky SL, Stanley PL, Fogarasi M, Ouwehand W, McCafferty J, Murphy G (2011) Cross-domain inhibition of TACE ectodomain. Proc Natl Acad Sci USA 108: 5578-5583.

Weisenthal LM, Dill PL, Kurnick NB, Lippman ME (1983) Comparison of dye exclusion assays with a clonogenic assay in the determination of druginduced cytotoxicity. Cancer Res 43: 258-264.

Zhang Y, Hegen M, Xu J, Keith JC, Jin G, Du X, Cummons T, Sheppard BJ, Sun L, Zhu Y, Rao VR, Wang Q, Xu W, Cowling R, Nickerson-Nutter CL, Gibbons J, Skotnicki J, Lin L-L, Levin J (2004) Characterization of (2 R, 3S)-2-([[4-(2-butynyloxy)phenyl]sulfonyl]amino)-N,3dihydroxybutanamide, a potent and selective inhibitor of TNF-alpha converting enzyme. Int Immunopharmacol 4: 1845-1857.

This work is published under the standard license to publish agreement. After 12 months the work will become freely available and the license terms will switch to a Creative Commons AttributionNonCommercial-Share Alike 4.0 Unported License.

Supplementary Information accompanies this paper on British Journal of Cancer website (http://www.nature.com/bjc) 